\title{
The Effect of Ten Life Skills on Quality of Life in Adolescents with Thalassemia
}

\author{
Hadis Zamanifar ${ }^{1}$, Houshang Alijani Renani ${ }^{2 *}$, \\ Bijan Keikhaie ${ }^{3}$, Elham Maraghi ${ }^{4}$, Hossein Komeili Sani ${ }^{5}$,
}

1. Master of Nursing, School of Nursing and Midwifery, Ahvaz Jundishapur University of Medical Sciences, Ahwaz, Iran

2. Department of Pediatric Nursing, Nursing Care Research Center for Chronic Diseases, School of Nursing and Midwifery, Ahvaz Jundishapur University of Medical Sciences, Ahvaz, Iran

3. Assistant Professor, Department of Pediatrics, Department of Blood and Cancer, School of Medicine, Ahvaz Jundishapur University of Medical Sciences, Ahvaz, Iran

4. Department of Statistics and Epidemiology, School of Public Health, Ahvaz Jundishapur University of Medical Sciences, Ahvaz, Iran

5. Department of Mental Nursing, School of Nursing and Midwifery, Ahvaz Jundishapur University of Medical Sciences, Ahwaz, Iran

\begin{tabular}{|c|c|}
\hline Article Info & ABSTRACT \\
\hline $\begin{array}{l}\text { Received: 2019/06/29; } \\
\text { Accepted: 2019/03/02; } \\
\text { Published Online: 2020/03/25 }\end{array}$ & $\begin{array}{l}\text { Introduction: Chronic diseases, including Thalassemia, have a profound effect } \\
\text { on the functioning and overall life of the individual, especially at an early age. Given } \\
\text { the low quality of life of adolescents with thalassemia and the importance of their } \\
\text { function in society, this study aimed to determine the impact of applying life skills } \\
\text { on quality of life in adolescents in Ahwaz in } 2018 \text {. }\end{array}$ \\
\hline
\end{tabular}

10.30699/ajnmc.28.2.144

Methods: This quasi-experimental study was performed on 84 adolescents with

Original Article thalassemia major referred to Thalassemia Clinic of Baqa'i Hospital, Ahwaz city, Iran. The study was conducted from 2018 to 2020. Adolescents were randomly divided into intervention and control groups. Both groups completed the demographic information questionnaire and the Kidney Screening Questionnaire for

Use your device to scan and read the article online

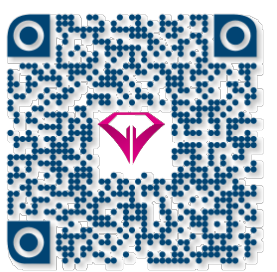
Quality of Life of the Teenager 52. Then the experimental group received the educational content (holding a class, Q\&A and booklet) for 6 sessions of 2-hour. The control group did not receive any training. Data were analyzed by SPSS 22 and Chisquare, independent t-test, and paired t-test.

Results: The results showed that the difference between the mean of quality of life in the two groups of control and intervention was not significant $(P<0.05)$ in pretest. Also, post-hoc test (assuming non-homogeneity of variances) also showed a significant difference in mean of quality of life in post-test in both intervention and control groups $(P<0.05)$.

Conclusion: Teaching ten life skills can have a significant impact on improving the quality of life of adolescents with thalassemia and can be used as an effective measure in this regard.

Keywords: Thalassemia major, Quality of life, Adolescent

Hooshang Alijani Renani, Department of Pediatric Nursing, Nursing Care Research Center for Chronic Diseases, School of Nursing and Midwifery, Ahvaz Jundishapur University of Medical Sciences, Ahvaz, Iran. Phone: 09161147163 Email: alijani-h@ajums.ac.ir

Copyright $(C 2020$, This is an original open-access article distributed under the terms of the Creative Commons Attribution-noncommercial 4.0 International License which permits copy and redistribution of the material just in noncommercial usages with proper citation.

How to Cite This Article:

Zamanifar H, Alijani Renani H, Komeili Sani H, Maraghi E, Komeili Sani H. The Effect of Ten Life Skills on Quality of Life in Adolescents with Thalassemia. Avicenna J Nurs Midwifery care. 2020; 28 (2) :144-153 
بر رسى تأثير بهكاركيرى مهارتهاى دهَانئ زندكى بر كيفيت زندگى نوجوانان مبتلا به تالاسمى

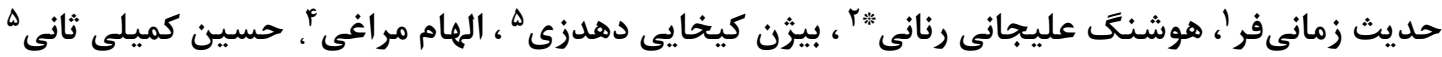

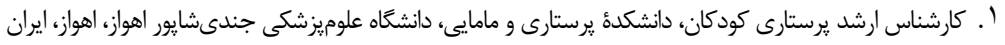

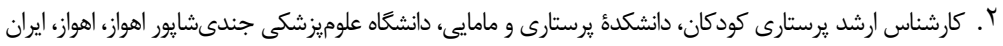

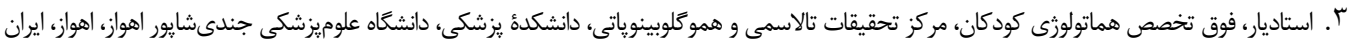

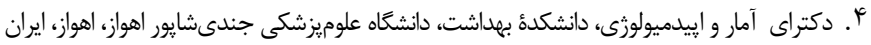

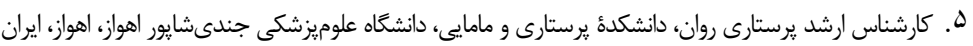

\begin{tabular}{|c|c|}
\hline جكيده & اطلاعات مقاله \\
\hline 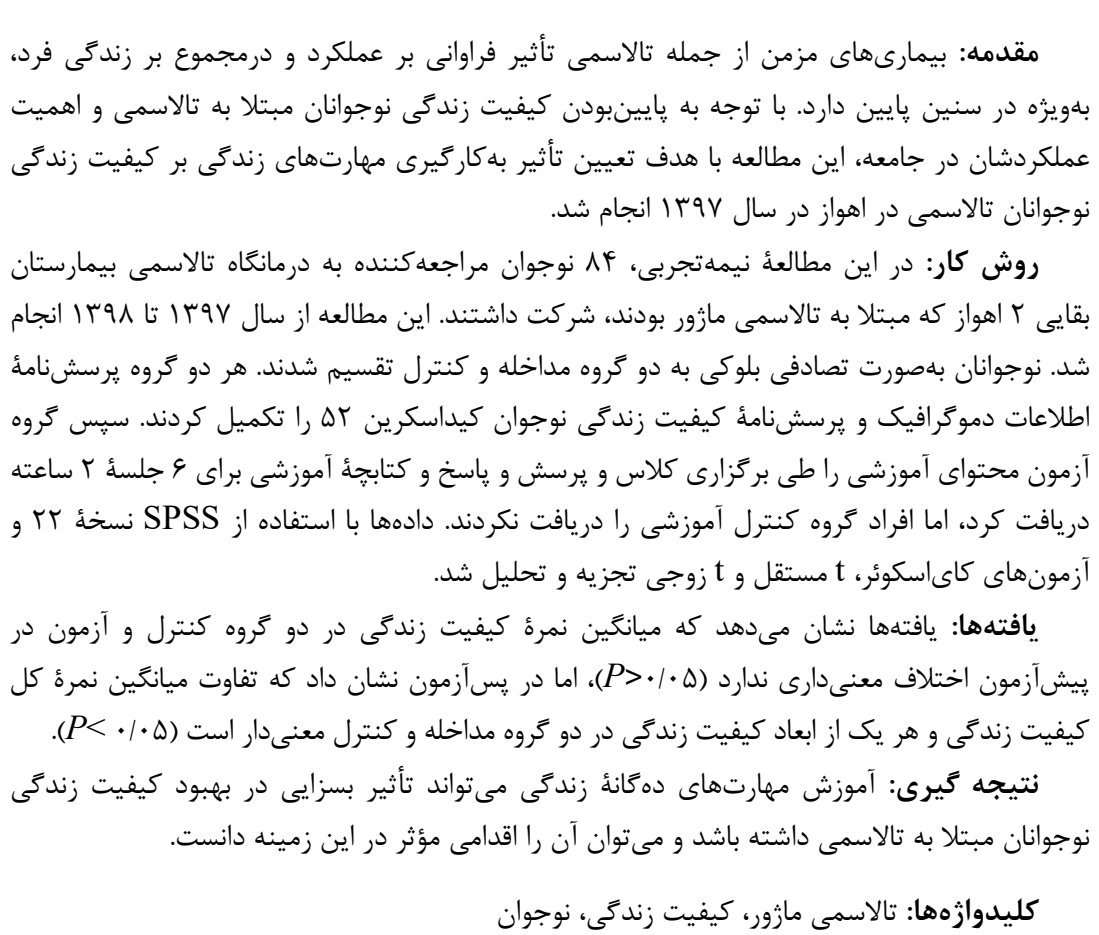 & 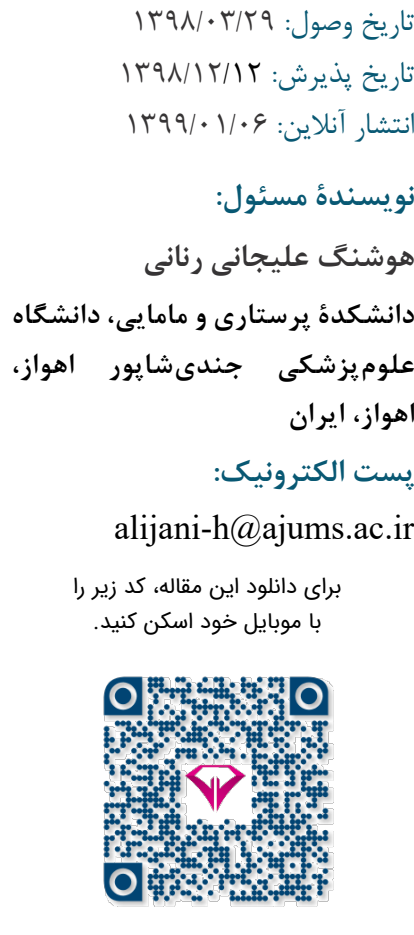 \\
\hline
\end{tabular}

حدود • r هزار بيمار و r تا r ميليون حامل زن اين بيمارى

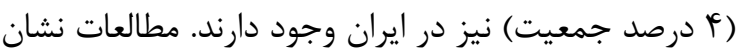
مى دهد كه • ا درصد ساكنان استانهاى خوزستان، بوشهر، هرمز گان، سيستان و بلوجستان، كرمان، گَيلان، مازندران،

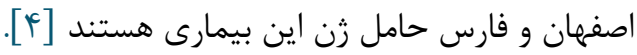
بسيارى از نوجوانان و جوانان مبتلا به بيمارىهاى مزمن

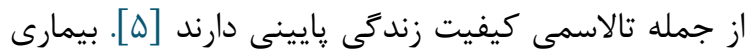

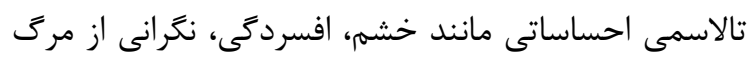

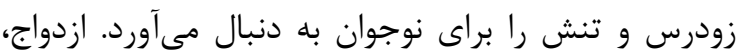

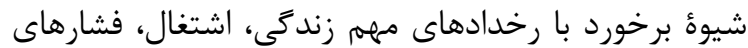
اقتصادى، نخرانىهاى عاطفى و مشكلات مربوط به خدمات رجدي
تالاسمى مازور شكل شايعى از يك آنمى ارثى در جهان است كه بلهدليل نقص در سنتز يكى از زنجيرههاى كلوبين، در هموَلوبين به وجود مى آيد و سبب كمخونى شديد در

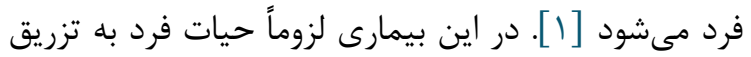

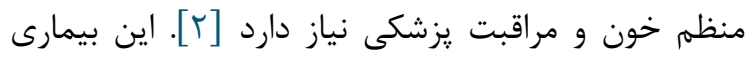

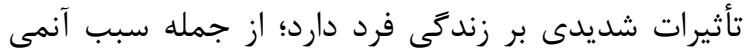

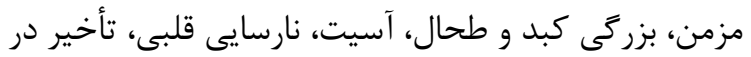

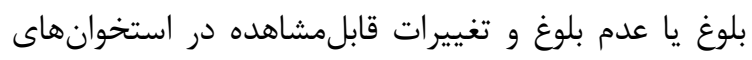

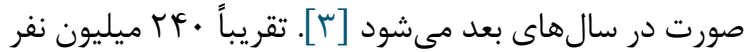
در سراسر جهان حامل زن اين بيمارى هستند و سالانه حدود

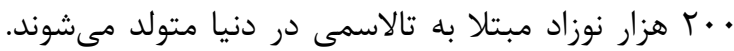


عملكرد مدرسه در مقايسه با كودكان سالم يايينتر است

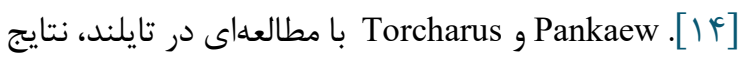
مشابهى را درمورد يايينبودن كيفيت زندكى كودكان و و

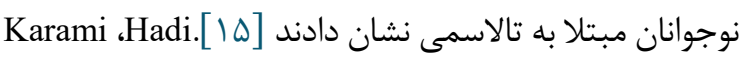
و Montazeri نيز در مطالعهاى در شيراز نتيجه كرفتند كه

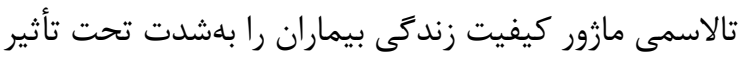

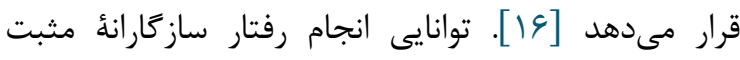

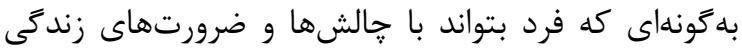

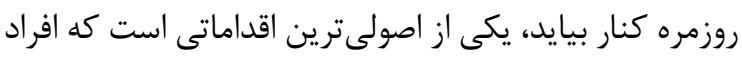

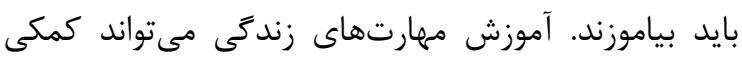

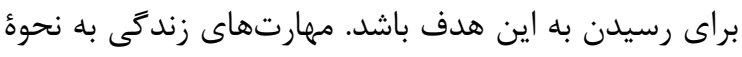

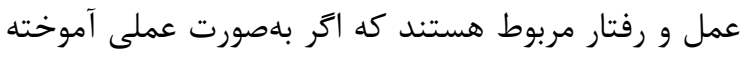

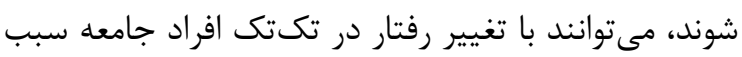

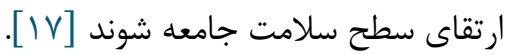
در ايران بيمارىهايى مانند تالاسمى مازور با توجه به شرايط مزمنبودن، صعبالعلاجبودن و هزينه هاى درمانى بالا و مههمتر از همه توجه مراكز بهداشتى و درمانى تنها به درماني

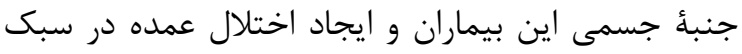

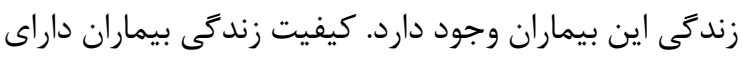

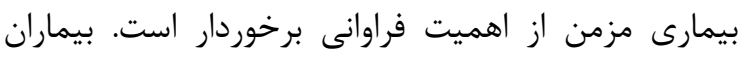

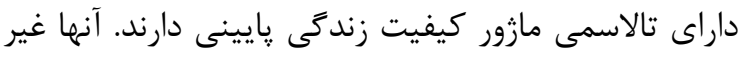

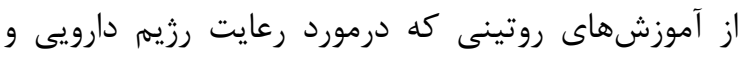

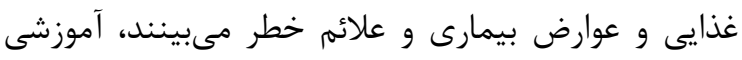
دريافت نمى كنند كه موجب ارتقاى كيفيت زندكى ايشان

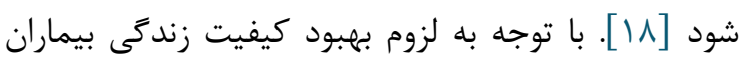

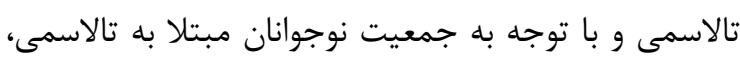

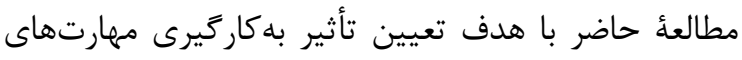

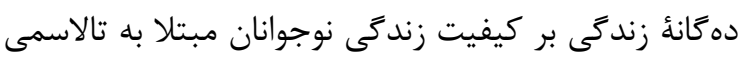

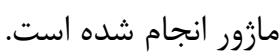

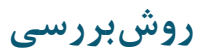

مطالعه حاضر، نيمهتجربى دوكروهى از نوع قبل و بعد

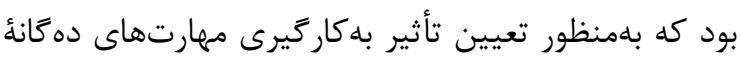

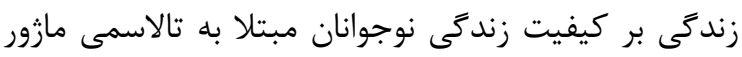

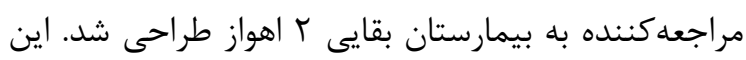

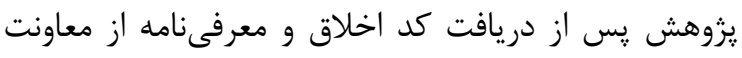

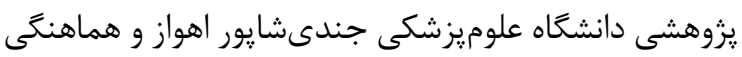

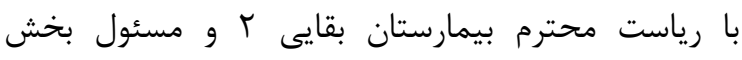

يزشكى از مشكلات دوره نوجوانى اين بيماران است [ع]؛

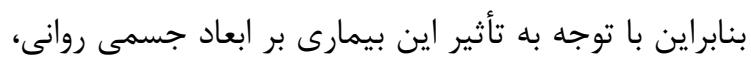

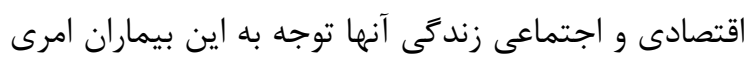

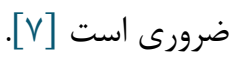
هدف اولئ درمان بلويزه در بيمارى مزمن، تقويت

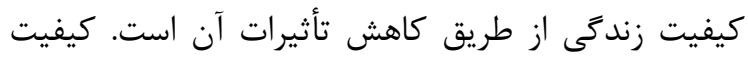

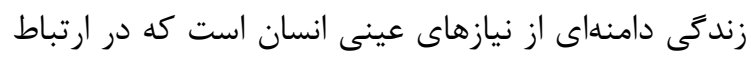

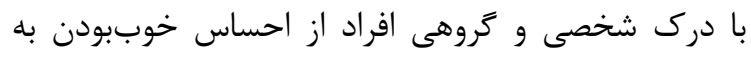

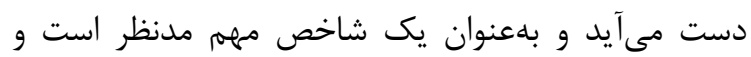

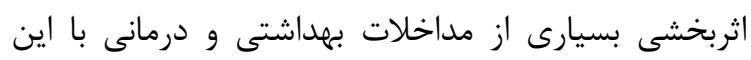

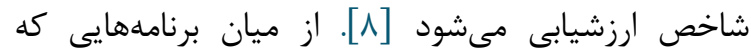

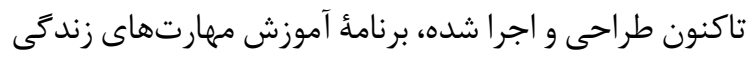

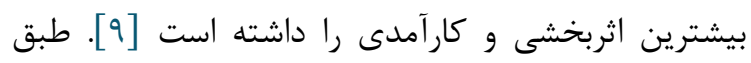

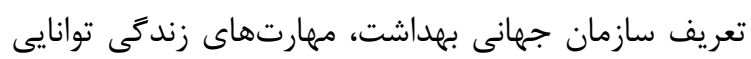

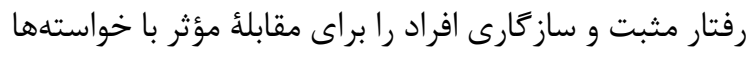

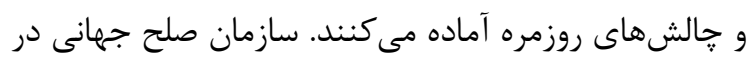

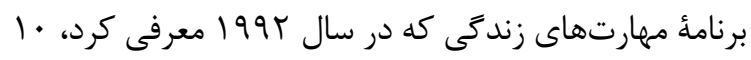

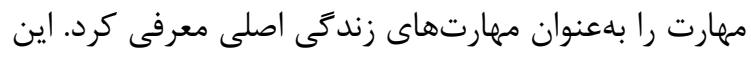

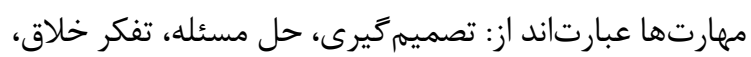

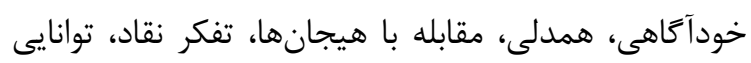

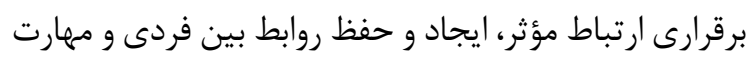

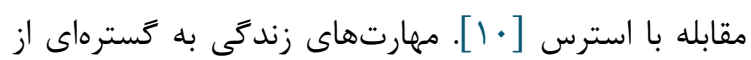

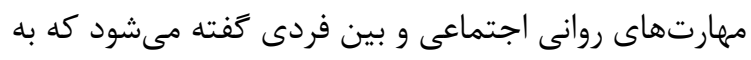

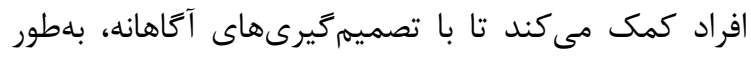

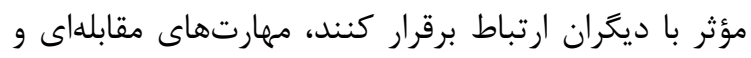

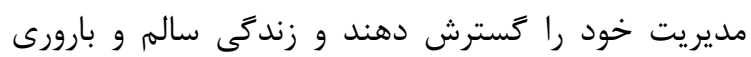

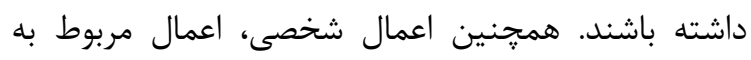

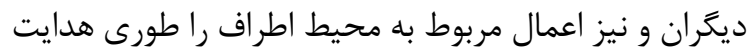

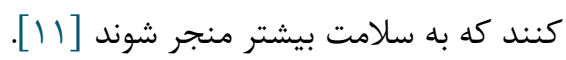

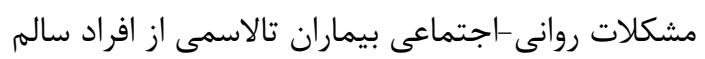

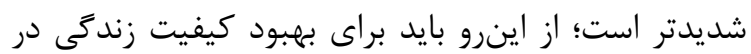

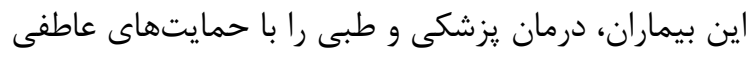

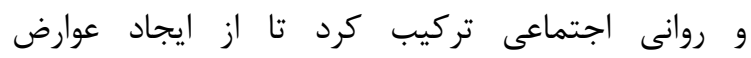

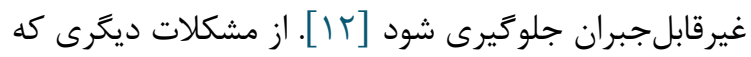

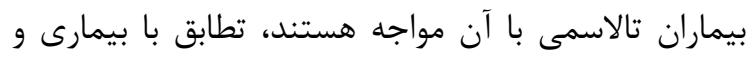

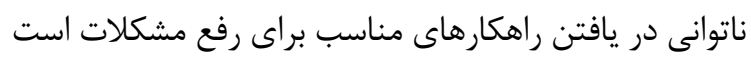

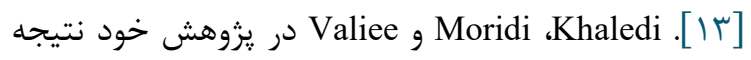
كرفتند كه كيفيت زندگى كودكان تالاسمى در حيطؤ درو 
وضعيت تأهل، وضعيت اقتصادى و تعداد اعضاى خانوادگى بود. بلمنظور بررسى كيفيت زندكى نوجوانان تالاسمى از يرسشنامة كيفيت زند

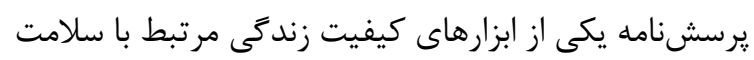

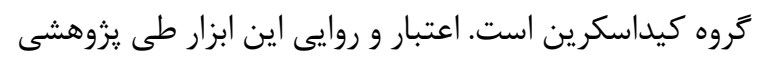

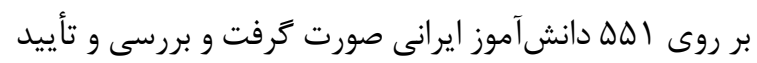

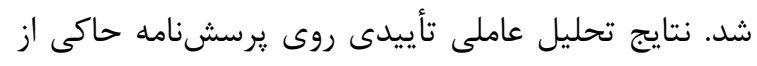

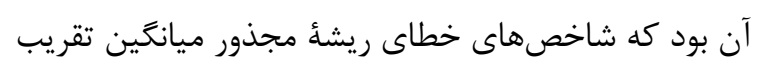
(RMSEA)

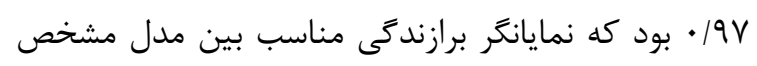

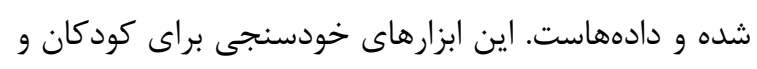

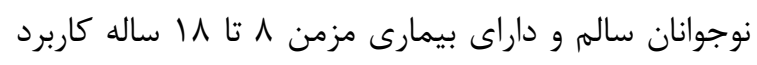

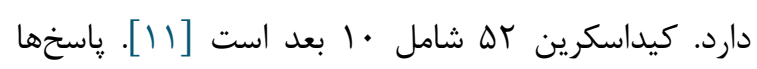

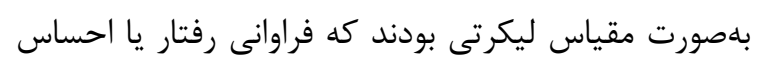

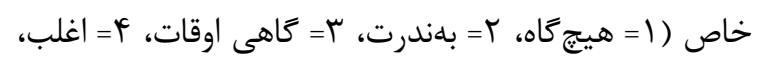

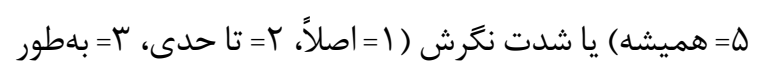

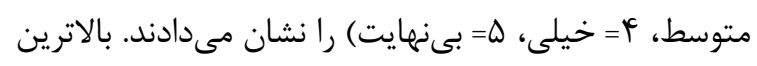

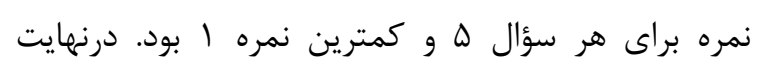

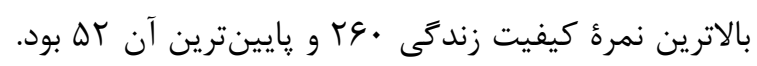

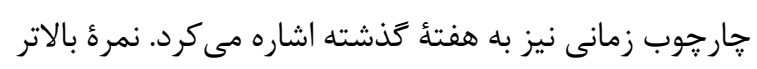

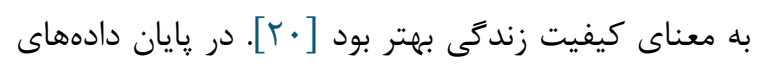
حاصل با استفاده از نرمافزار SPSS Inc., ( (Chicago, IL., USA و متغيرهاى كمى بهصورت ميانكين، انحراف معيار، حداقل و حداكثر و متغيرهاى كيفى نيز

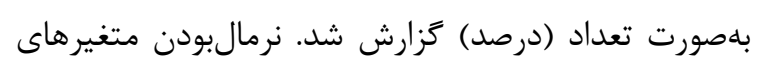

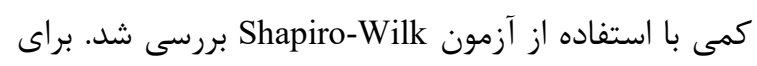
بررسى ارتباط متغيرهاى كيفى از آزمون كاى اسكوئر (آزمون

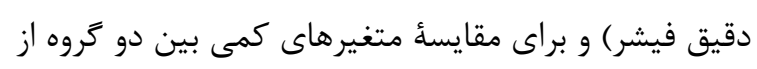

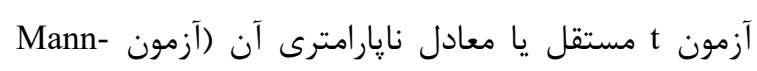
(Whitney

$$
\text { كوجكتر از ه • • • بود. }
$$

تالاسمى، همجنين گرفتن رضايتنامه آكاهانهُ كتبى از

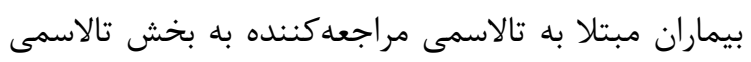

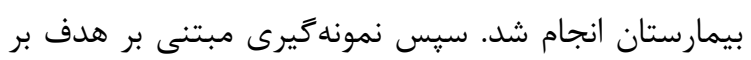

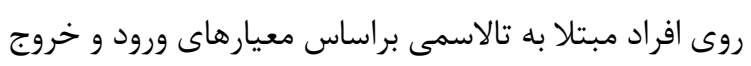

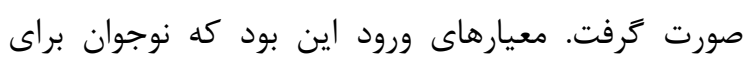

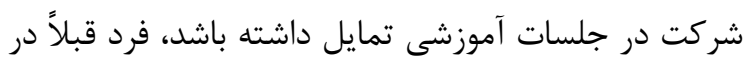

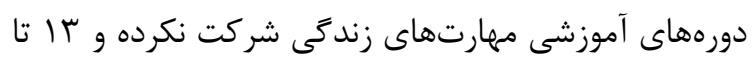

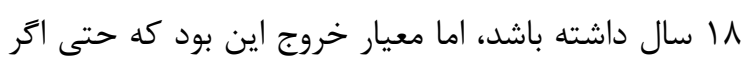

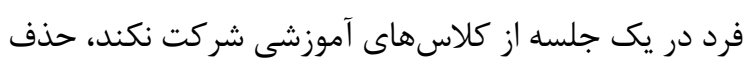

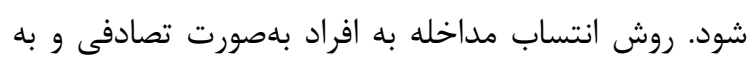

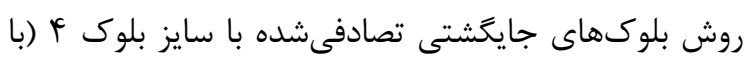

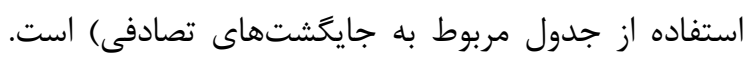

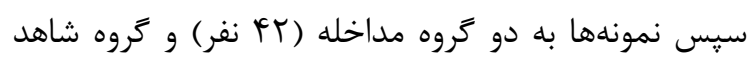

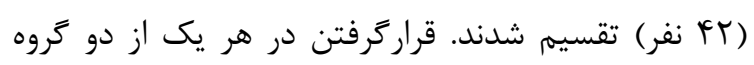

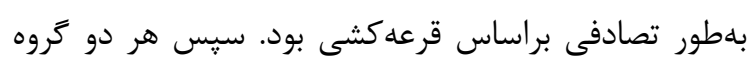

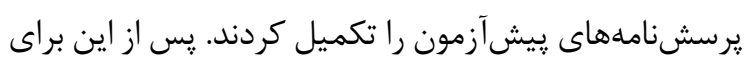

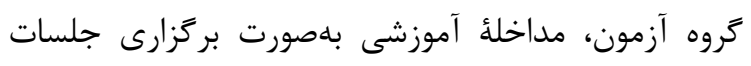

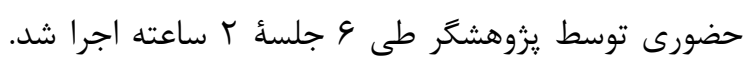

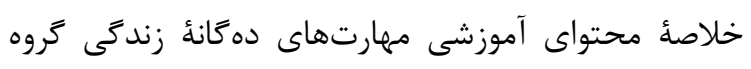

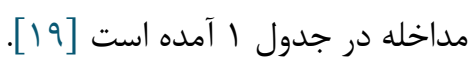

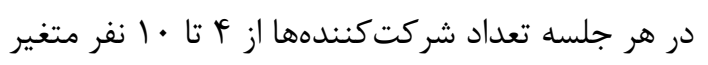

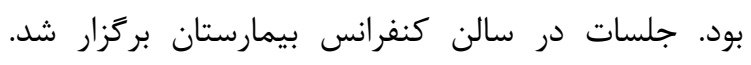

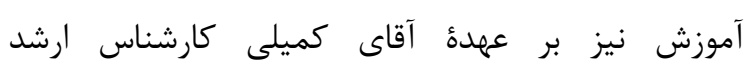

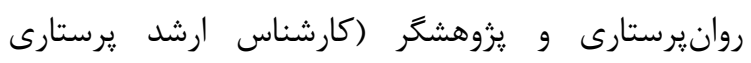

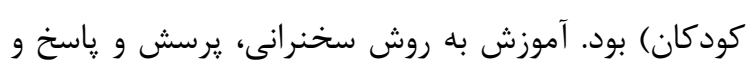

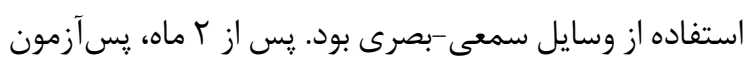

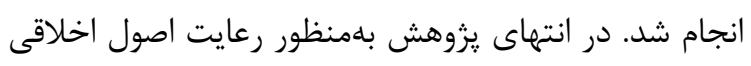

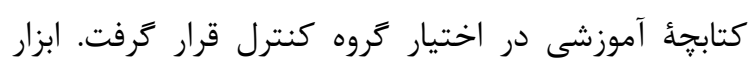

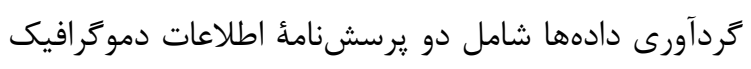

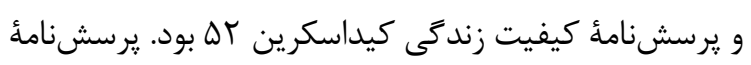
اطلاعات جمعيتشناختى شامل سن، جنس، تحصيف زيلات،

جدول ا. خلاصةُ محتواى آموزشى مهارتهاى دهَانهُ زندكى كروه مداخله

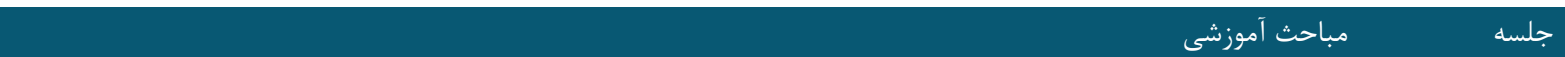

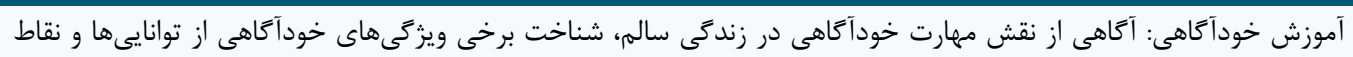

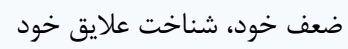

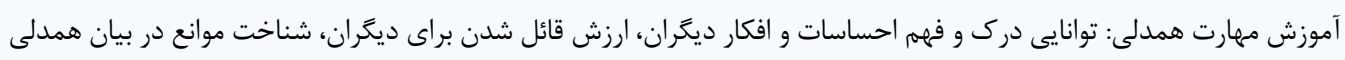

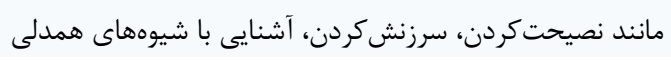

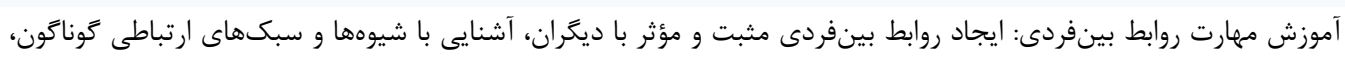

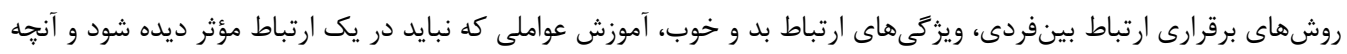


بهتر است انجام شود. آشنايى با انواع برسشها در ارتباط مؤثر، اجزاى كلامى و غير كلامى، شيوههاى ارتباطى و تمرين ارتباط

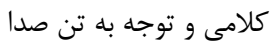

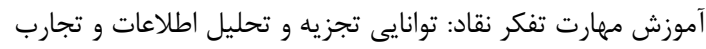

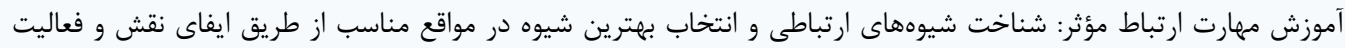

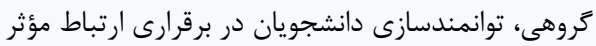

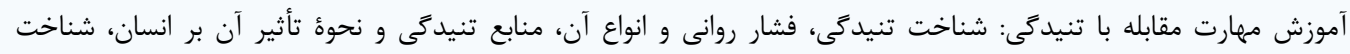

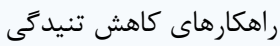

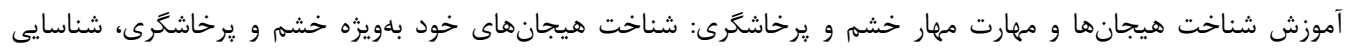
جهارم

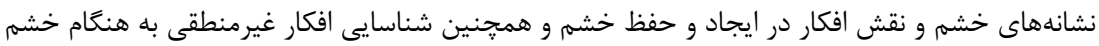

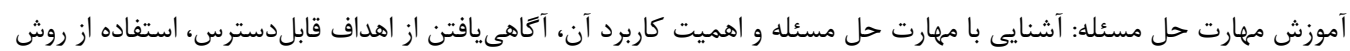

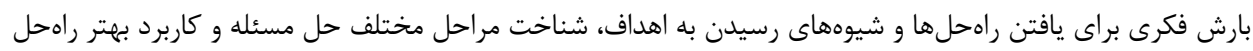

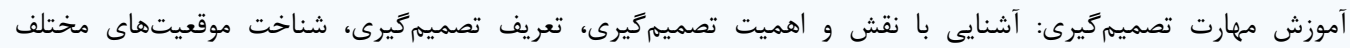

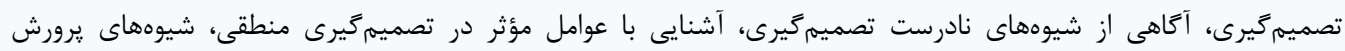
تصميم كيرى و مر احل جهار كانه إنه آموزش مههارت تفكر خلاقي: تفكر درمورد يكى مسئله و همأه راهحله هاى موجود براى حل آن، انتخاب بهتر ين راهحل، بررسى عواقب راهماى ديكر مرور تمام مباحث كذشته

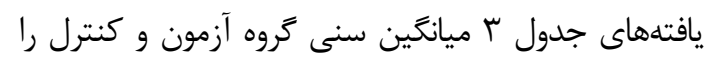

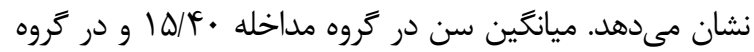

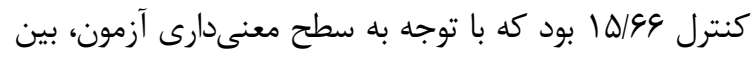

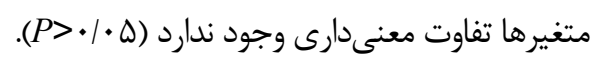

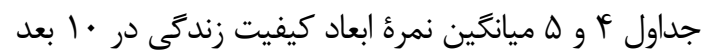
جسمانى، روانى، ادراك از خود، خودمختارى، ارتباط با والدين،

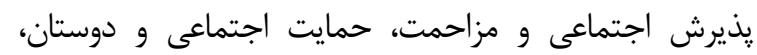

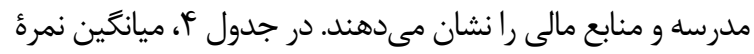

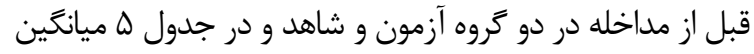

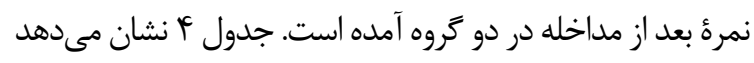

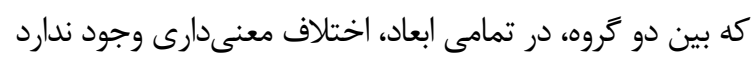

. $(P>\cdot / \cdot \bullet \Delta)$ اكر به ميانكين نمرهها در تروه شاهد و كروه مداخله قبل از ماز

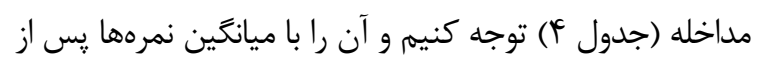
مداخله (جدول ه) مقايسه كنيم، مشاهده مىشود ميانكين نمره در كروه شاهد تغييرى ندارد؛ درحالى كه اين ميانكَين در كروه

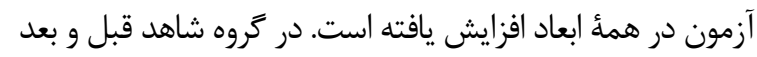

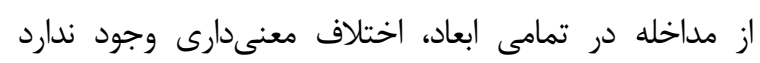

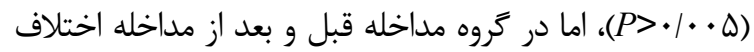

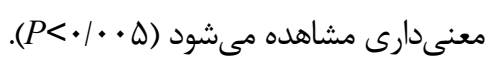

در اين مطالعه، عا نوجوان مبتلا به تالاسمى مازور شركت

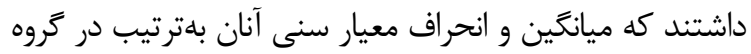

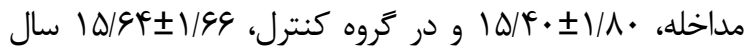

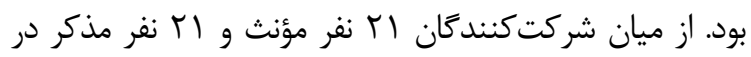

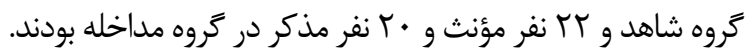

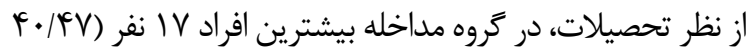

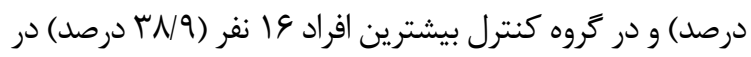
مقطع راهنمايى بودند. از نظر وضعيت اقتصادى، در كرو كروه مداخله

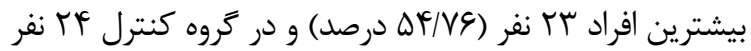
(دV/I)

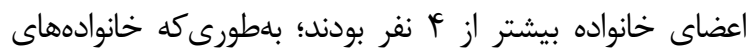

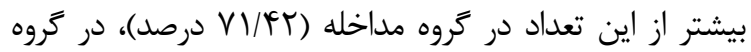

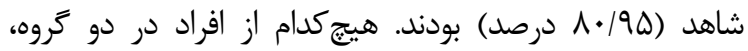

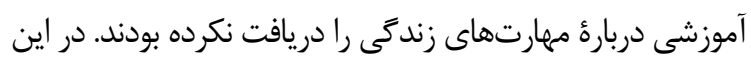

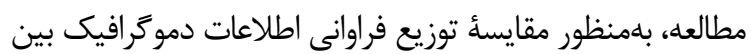

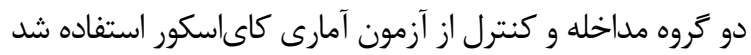

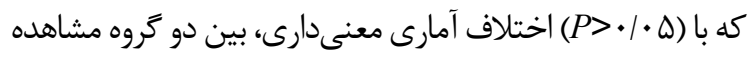

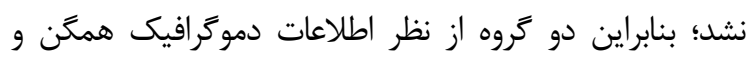

مقايسهيذير هستند (جدول r و ل). 
حديث زمانىفر

جدول r. توزيع فراوانى نسبى و درصد واحدهاى مورد يزوهش براساس مشخصات دموكر افيك والدين در دو گروه مداخله و كنترل

\begin{tabular}{|c|c|c|c|c|c|c|}
\hline \multirow[t]{2}{*}{ P-value } & \multicolumn{2}{|c|}{ تروه مداخله } & \multicolumn{2}{|c|}{ تروه كنترل } & \multirow{2}{*}{ رده بندى } & \multirow{2}{*}{ شتغير آمارى } \\
\hline & درصد & تعداد & درصد & تعداد & & \\
\hline \multirow{2}{*}{$>.199$} & $\Delta T / T^{C}$ & rt & Q. & r) & مؤنث & \multirow{2}{*}{ جنسيت } \\
\hline & $\mathrm{FV} / \mathrm{s}$ & $r$. & $\Delta$. & rI & مذكر & \\
\hline \multirow{5}{*}{$\cdot / r \cdot V$} & $f / v \varepsilon$ & r & . & · & بى سواد & \multirow{5}{*}{ تحصيلات } \\
\hline & $11 / 9$. & $\Delta$ & $19 / 4$ & $\wedge$ & ابتدايى & \\
\hline & $r \cdot / F V$ & IV & rN/q & 19 & راهنمايى & \\
\hline & TN/DV & ir & $r 8 / 19$ & 11 & دبيرستان & \\
\hline & $\mid F / T \Lambda$ & 9 & $19 / 99$ & $v$ & دانشگاهى & \\
\hline \multirow{3}{*}{.$/ v 99$} & $r M / \Gamma^{\leftarrow}$ & 9 & $19 / V$ & $v$ & ضعيف & \multirow{3}{*}{ اقتصادى وضعيت } \\
\hline & $\Delta F / V G$ & זr & $\Delta V / \mathrm{I}$ & re & متوسط & \\
\hline & $r \mu / \Lambda$. & 1. & T & 11 & خوب & \\
\hline \multirow{2}{*}{$\cdot / V \cdot 9$} & TN/DV & Ir & $19 / \cdot{ }^{c}$ & $\wedge$ & ع أنفر & \multirow{2}{*}{ اعضاى خانواده } \\
\hline & VIRT & $r \cdot$ & $1 . / 90$ & me & بيشتر از ع أفر & \\
\hline
\end{tabular}

جدول r. مقايسُٔ ميانغين سن واحدهاى مورد يخوهش در دو گروه كنترل و مداخله

جدول F. مقايسهُ ميانعين و انحراف معيار در دو تروه مداخله و كنترل، قبل از مداخله

\begin{tabular}{|c|c|c|c|c|c|}
\hline \multirow{2}{*}{$\begin{array}{r}P- \\
\text { value }\end{array}$} & \multicolumn{2}{|c|}{ كنترل } & \multicolumn{2}{|c|}{ مداخله } & 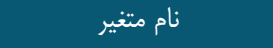 \\
\hline & انحراف معيار & ميانگين & انحراف معيار & ميانگين & از مداخله \\
\hline$\cdot \mid \Delta \& \Delta$ & $r / 9 \Lambda$ & $10 / \kappa^{c}$ & $r / \Delta \Lambda$ & $\mid f / M$ & جسمانى \\
\hline$\cdot 1 \cdot \mathrm{V}^{\mathrm{c}}$ & $r / v \varepsilon$ & $1 \% / \Lambda$. & $r / T \Delta$ & سואוNו & روانى \\
\hline$\cdot / \Delta \vee \varepsilon$ & $r / 4)$ & If/VE & $r / r q$ & $\mid f / 19$ & خلق \\
\hline.$/ . \Delta T$ & $T / \Delta S$ & $1 \Delta / T \omega$ & r/Ar & $1 r / 9 r$ & 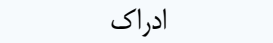 \\
\hline Tr & 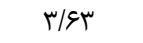 & $\mid F / \Delta T$ & سו/ & $1 r / \varepsilon q$ & خودمختارى \\
\hline . IRAT & $r / q \vee$ & 1ه/TI & $r / 9 \varphi$ & $\mid F / \Delta r$ & ارتباط با والدين \\
\hline $.1 . \mu \mathrm{F}$ & س سو/r & $10 / 4 V$ & $r / M$ & $10 / \mathscr{F V}$ & يذيرش اجتماعى و مزاحمت \\
\hline عسو/. & $T / V \Delta$ & $1 \pi / 4$ & $r / 9 q$ & $15 / \cdot 9$ & حمايت اجتماعى و دوستان \\
\hline.$/ \cdot r \mathrm{r}$ & r/lt & $\mid \omega / \ldots$ & $r / 9 \Lambda$ & $\mid r / \Delta V$ & 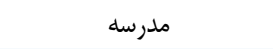 \\
\hline $.1 . .9$ & ( & $\mid \Delta / \ldots$ & $r / F Q$ & $15 / \cdot 9$ & منابع مالى \\
\hline
\end{tabular}


جدول ه. مقايسُٔ ميانگين و انحراف معيار در دو كروه مداخله و كنترل، بعد از مداخله

\begin{tabular}{|c|c|c|c|c|c|}
\hline \multirow{2}{*}{ P-value } & \multicolumn{2}{|c|}{ كنترل } & \multicolumn{2}{|c|}{ مداخله } & \multirow{2}{*}{ نام متغير } \\
\hline & انحر اف معيار & ميانكَين & انحراف معيار & ميانگين & \\
\hline$<\cdot / \cdot+1$ & $r / v q$ & $\mid f / \Lambda$ & T/rQ & سואו & جسمانى \\
\hline$<\cdot / \cdots 1$ & $r / \cdot r$ & $\mid g / Q F$ & $r / v$ & $r / 99$ & بعد روانى \\
\hline$<+1+\cdot 1$ & r/lq & $10 / 9 \Delta$ & $\Gamma / 9 \Delta$ & 19/Dr & 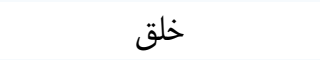 \\
\hline$<\cdot / \cdot \cdot 1$ & $\varphi / .9$ & $|Q / V|$ & 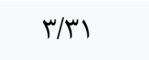 & 10 & 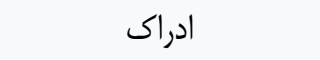 \\
\hline$<\cdot / \cdot+1$ & $r / 9)$ & $\mid f / v e$ & $r / v q$ & 19/Dr & خودمختارى \\
\hline $.1 \cdot+r$ & 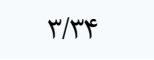 & $10 / 09$ & $r / q V$ & IV/9V & ارتباط با والدين \\
\hline$\cdot / \cdot 1$ & r/9 T & $18 / \mu$ & $r / v$. & $M / \Delta V$ & حمايت اجتماعى و دوستان \\
\hline $.1 \cdot r+$ & r/9 & $19 / \mu$ & $r / v$. & $M / \Delta V$ & يذيرش اجتماعى \\
\hline$<+1+\cdots 1$ & ו וس/r & $\mid \omega / \cdots$ & $r / 90$ & IV/AD & 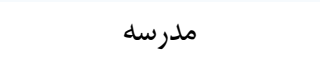 \\
\hline.$/ \cdot r$ & $r / \Delta \Lambda$ & $1 r / 94$ & r/IV & $19 / 4$ & منابع مالى \\
\hline
\end{tabular}

سلامت جسمى و در كل افزايش كيفيت زندگى شده است

برنامةٔ آموزش مهارتهاى زندگى از جمله كاربردهاى

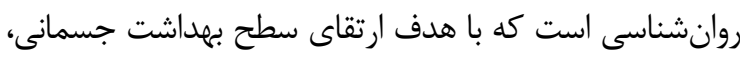

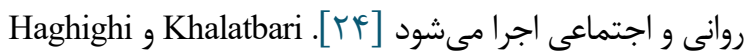

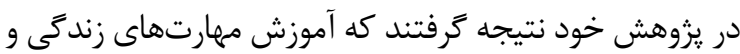

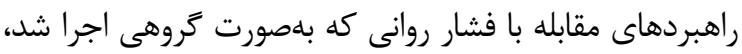
سبب افزايش سلامت روان (كه يكى از ابعاد كيفيت زندگ

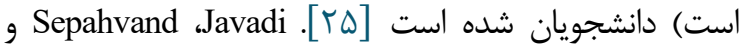
Mahmudi

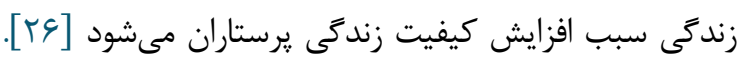

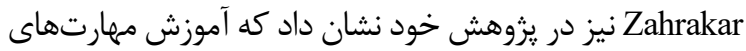
زندگى موجب افزايش كيفيت زندگى دانشجويان شده است؛ بلهورى كه كنش جسمانى، سلامت جسمانى و سلامت عمومى آنى كروه آزمايش افزايش يافته است [YV] آموزش مهارتهاى زندگى مىتواند افراد را در استفاده از راهبردهاى مؤثر و سازشيافته براى مقابله با مشكلات مروني روزمره

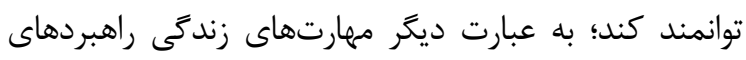
مقابلهاى مهمى هستند كه توانايى ييشرفت شخصى و اجتماعى رونى

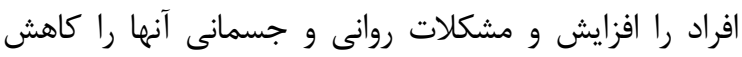

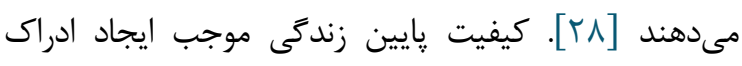

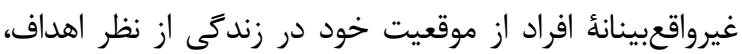

هدف مطالعهُ حاضر، تعيين تأثير بهكارگيرى مهارتهاى دهانأ زندگى بر كيفيت زندگى نوجوانان مبتلا به تالاسمى

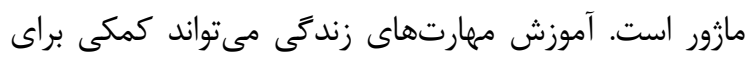

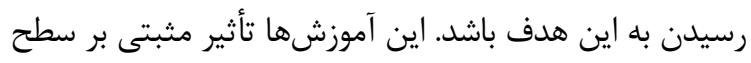

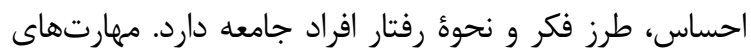
زندگى مربوط به نحوه عمل و رفتارند و اگر بلهورت عملى

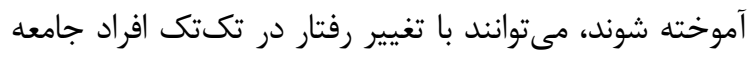
سبب ارتقاى جامعه شوند [ [ب]. نتايج نشان مى دهد بعد از مداخله، ميانگين نمرة كيفيت زندگى در همهُ ابعاد و ميانگين نمره كل كيفيت زندگى افزايش

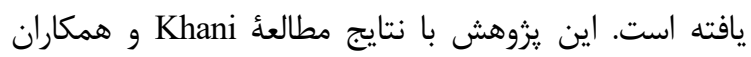

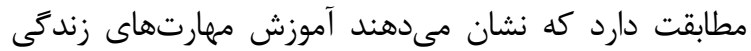
مىتواند در بهبود كيفيت زندگى و شاخصهاى روانى بيماران

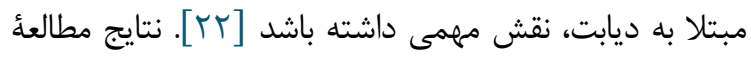

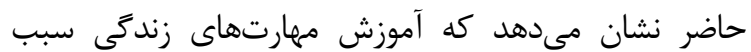
افزايش سلامت روانى و سلامت جسمانى گروه مداخله شده

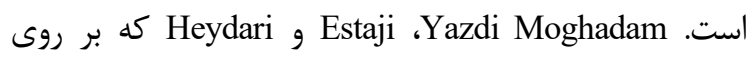
يرستاران شاغل در بيمارستانهاى شهر سبزوار انجام گرفت، مشخص شد كه كيفيت زندگى بيشتر آنها متوسط است. براساس نتايج اين تحقيق، آموزش مهارتهاى زندكى سبب ديب دئن

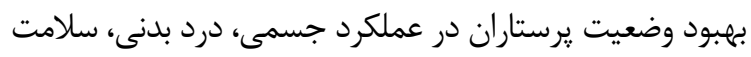

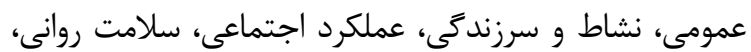


عواطف و احساسات خود را بهخوبى بشناسد و بهدقت ارزيابى كنند. همجنين مىتوانند افكار منطقى و غيرمنطقى مرتبط با باليا

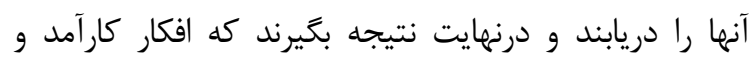

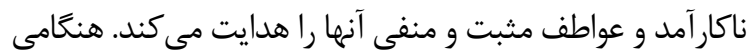

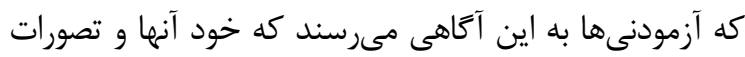

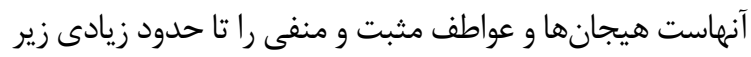

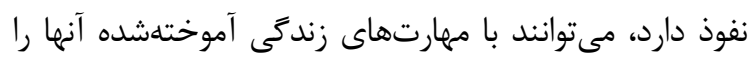

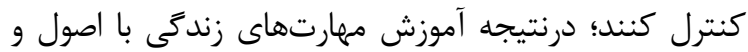
مهارتهايى كه آموزش مىدهد، سبب افزايش سلامت عمومى مهي و كيفيت زندگى مىشود. [بس]

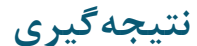

يافتههاى بلهدستآمده در مطالعهُ حاضر نشان مىدهد كه

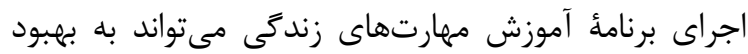

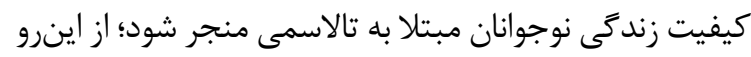

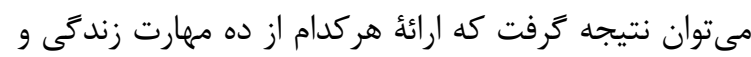
بهكارگيرى آن از سوى همهٔ افراد، بهويزه افراد داراى بيمارى

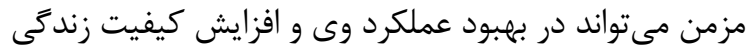

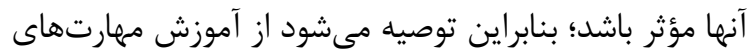
دهكانهٔ زندكى بهعنوان شيوهاى مؤثر در آموزش بيماران مبتلا

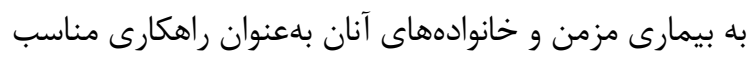
براى ارتقاى سطح كيفيت زندىى استفاده شود.

\section{سياسگزارى}

اين مقاله بركرفته از ياياننامٔ كارشناسى ارشد يرستارى با كد اخلاق (IRCT20181202041825N1) است كه با حمايت مالى دانشگاه علوميزشكى جندى شايور اهواز انجام شده است. بدينوسيله از معاونت محترم تحقيقات و فناورى اين دانشخاه و همجنين از بيماران ارجمند كه بدون همكارى آنها انجام اين دمقين يزوهش غيرممكن بود صميمانه سياسگز ارى مى كنيم.

$$
\text { تعارض در منافع }
$$

بين نويسندًان هيجَّونه تعارضى در منافع وجود ندارد

$$
\text { منابع مالى }
$$

منابع مالى اين مطالعه توسط نويسندكان تامين شده است.
انتظارات و اولويتهاست. به همين دليل، آموزش مهارتهاى

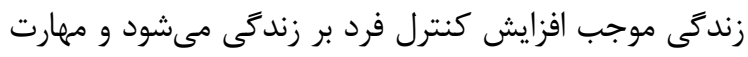
تصميمَيرى و حل مسئله را بهطور معقول و مؤثر به او او مىآموزد. جنين آموزشهايى هم در بهبيود و حداقل درمان نسبى وضعيت جسمانى و هم بهبود وضعيت روانى مؤثر هستند. نوجوانان مبتلا به تالاسمى مازور در مقايسه با همسالان

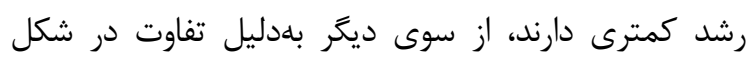
ظاهرى خود احساس حقارت و اعتمادبهنفس كمى دارند [ [ج].

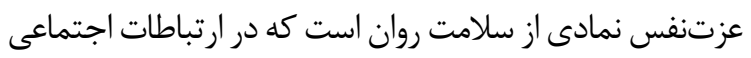
انسان را در مقابل اضطراب و اختلالات جسمانى حمايت

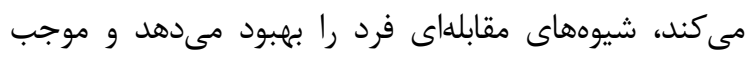
ارتقاى سطح سلامت روان مىشود. عزتنفس مانند يك مهارت

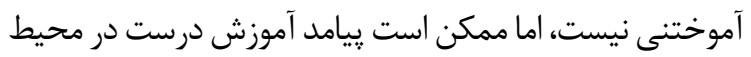

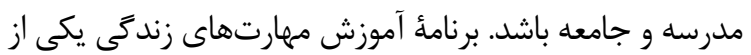
برنامههايى است كه به افزايش عزتنفس فرد منجر مىشود و

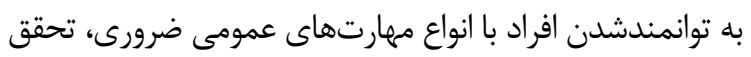

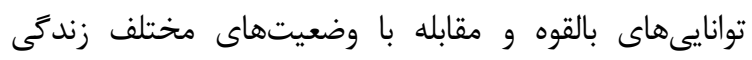

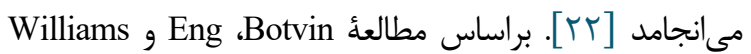

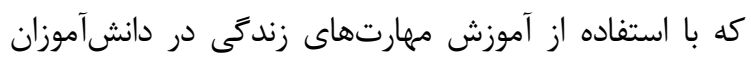
بلمنظور بِيشگيرى از سوءمصرف مواد انجام شده است، نشان آنان

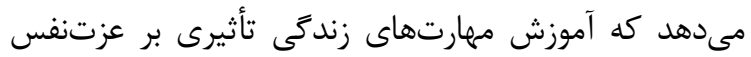

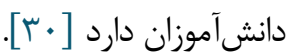

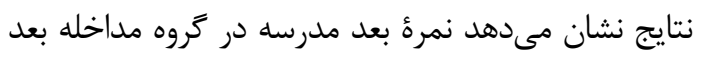

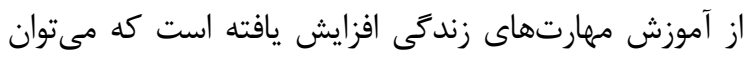

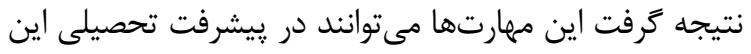

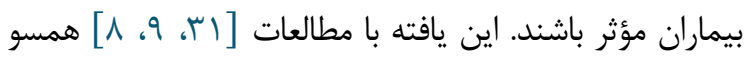
بود كه در نشان دادند آموزش هر كدام از مهارتهاى بات دمكانه

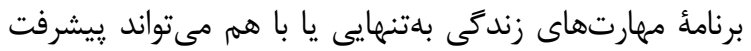

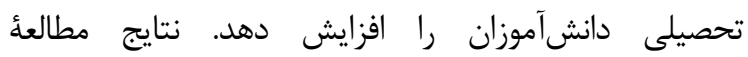
Sepahamansour مركز نشاندهندة تأثير مثبت برنامه در ارتقاى ميزان انكَيزء

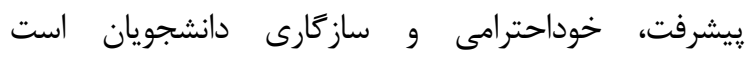

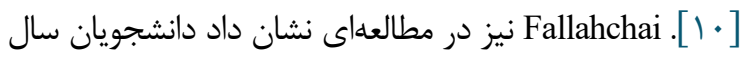

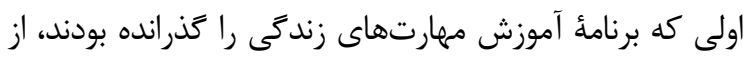
ساير دانشجويان همدوره خود، پيشرفت تحصيلى بيشترى

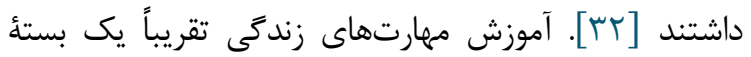

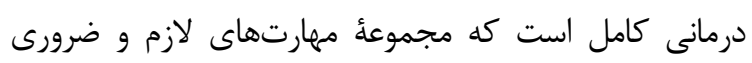
زندكى را به افراد آموزش مىدهد و كمك مى كند تا افراد 


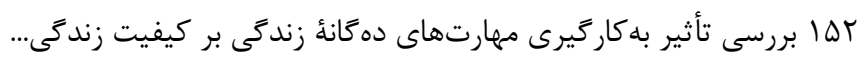

\section{References}

1. Babar M, Shan M. Significance of combo chelation therapy over mono chelation therapy in patient with thalassemia. Journal of Pharmaceutical Sciences and Research. 2010; 2(12): 837-43.

2. Awadallah SM, Atoum MF, Nimer NA, Saleh SA. Ischemia modified albumin: An oxidative stress marker in $\beta$-thalassemia major. Clinica Chimica Acta. 2012 May 18;413(9-10):907-10. [DOI:10.1016/i.cca.2012.01.037] [PMID]

3. Yalçn SS, Durmusoglu-Sendogdu M, Gümrük F, Ünal S, Karg E, Tugrul B. Evaluation of the children with $\beta$ thalassemia in terms of their self-concept, behavioral, and parental attitudes. Journal of pediatric hematology/oncology. 2007 Aug 1;29(8):523-8. [DOI:10.1097/MPH.0b013e3180f61b56] [PMID]

4. Azami M, Parizad N, Sayehmiri K. Prevalence of hypothyroidism, hypoparathyroidism and thefrequency of regular chelation therapy in patients with thalassemia major in Iran: a systematic review and meta-analysis study. Iranian Journal of Pediatric Hematology and Oncology. 2016 Nov 10;6(4):261-76.

5. Madmoli Y, Beiranvand R, Korkini N, Mashalchi H, Karimi H, Madmoli M. Comparison of health-related quality of life in beta thalassemia major and healthy people in Dezful in 2015. Iranian Journal of Nursing Research. 2016 Apr 10;11(1):9-16.

6. Mohammadi S, Tajvidi M, Ghazizadeh S. The relationship between spiritual well-being with quality of life and mental health of young adults with betathalassemia major. Scientific Journal of Iranian Blood Transfusion Organization. 2014 Jun 1;11(2).

7. Knowledge \& Research in Applied Psychology Vol 15. No. 3 (Continuous No. 57)- Autumn 2014 PP: 8191.

8. Greenberg MT, Weissberg RP, O'Brien MU, Zins JE, Fredericks L, Resnik H, et al. Enhancing schoolbasedprevention and youth development through oordinated social, emotional, and academic learning. American. 9. Amirian K. P-834-Effect of life skills education on academic achievement of first year high school male students. European Psychiatry. 2012 Jan 1;27:1. [DOI:10.1016/S0924-9338(12)75001-0]

9. Sepahamansour M. [Tasireamozeshemaharatheyezendegi bar angizeyepishraft, khodehteramivasazgareiejtemaee]. AndishevaRaftar. 2008;2(6):85-93.

10. Steptoe A, Wardle J. Life skills, wealth, health, and wellbeing in later life. Proceedings of the National Academy of Sciences. 2017;114(17):4354-9.

11. Shasati S, Mir Hehjo S, Masouleh S, Sigarodi A,Roshan Z. Study of life skills of children with thalassemia11-19Y who referred to educational and therapeutic centers of Rasht from the viewpoint of their mothers in the year,Two Quarterly Nursing and Midwifery Schools of Guilan Province, 2010. Year 20, No. 63, P16-21

12. TabursiB. Comparison of the Problems of Thalassemia Major Patients withIrregular Follow-up of Principles of Therapy in Patients with Thalassemia Treatment
Center in Tehran, Tehran, Iran.2010, Vol. 4, No. 1, p. 33

13. KhalediS;Moridi G; valiee S; Comparison The Quality Of life Of Healthy And Thalasemic Children Iranian jornal Of Nursing Research.2013;8(2):87-94. (Persion).

14. Torcharus K, Pankaew T. Health-related Quality of Life in Thalassemia Treated with Iron Chelation. Southeast Asian J Trop Med Public Health. 2011;42(4):951-9.

15. Hadi N. Karami d, Montazeri A.]Health-related quality of life in patients with thalassemia major (Persian)]. Payesh. 2009;8(4):387-93.

16. 17 Rashidi Nejad M, Miri S, Bahramnejad A. The effect of life skills education on emotional, think, behavior in situational and different times of Bam nursing school students. Journal of Qualitative Research in Health Sciences. 2011 Jun 21;10(2):47-53.

17. Fatemeyan Rad F, Mostanbt N, Zoladl M. The effect of training on coping with stress, anxiety and depression among patients with special diseases. Armaghane danesh. 2013 Dec 15;18(9):777-86.

18. Ebrahimi, A. A Study of the Group Effectiveness of Life Skills Training on Parent-Adolescent Conflicts2012. Master thesis. Faculty of Education and Psychology, Islamic Azad University, Arak Branch

19. Nick Azin A, NainianM, ShaeeriM. Reliability and Reliability of Kids-Scan-52 Health-Related Quality of Life Questionnaire (KIDSCREEN-52) in Iranian students. Journal of Health Research.2014, 3 (3): 210224

20. Farmahinifarahani, M. Sobhaninejad, M. \& Pidad, F. (2010). ComparativeStudy of the Life Skills of Students in Philosophical and Non-Philosophical Sciencesof the Schools of Humanities in Tehran State Universities. Higher EducationCurriculum Studies, 142-158. (Persian).

21. Khani F, Samsam Shariat MR, Mehdad A, Taki F, Kourang Beheshti M, Hekmatravan R. The effecti of life skills training on improving SCL-90 psychological indicators and quality of life in patients with diabetes. JSR. 2015 Jan 15;15(57):81-91.

22. Yazdi Moghadam H, Estaji Z, Heydari A. Study of the quality of life of nurses in Sabzevar hospitals in 2005 2006. J Sabzevar Univ Med Sci. 2009;16(1):50-6.

23. Raiisee R. Impact of counseling sessions on life skills training on mental health of children of Journal of Shahrekord University of Medical Sciences / Volume 14, Issue 4, Oct. and Nov. 2012 / 30-37

24. Khalatbari J, Haghighi FA. The effect of lifeskills and coping strategies with stress training on mental health of girl students. Knowledge Res App Psycho. 2011 Jan $1 ; 12(2): 29-37$.

25. Javadi M, Sepahvand MJ, Mahmudi H. The effect of life skills training on quality of life in nurses of Khorramabad Hospitals. Scientific Journal of

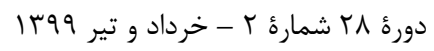

$$
\text { مجله مراقبت يرستارى و مامايى ابنسينا }
$$


حديث زمانىفر سها

Hamadan nursing \& midwifery faculty. 2013 May 15;21(1):32-42.

26. Zahrakar,K.Effectiveness of problem solving skills training on self-efficacy of female student students in Tehran2010.13 - 150: (3) 5

27. Akbari, M.P. Shaghaghi, f. Behrouzian, M. The Impact of Problem Solving Skills Training on Students' Test Anxiety. Transformational Psychology Quarterly: Iranian Psychologists, 67-74,29(8)

28. Salimi BH, Abedi F. The effectiveness of life skills training on anxiety, depression and happiness of secondary school students mothers in Karaj city. JCP. 2013;11(3):29-48.

29. Botvin GJ, Eng A, Williams CL. Preventing the onset of cigarette smoking through life skills training. Preventive medicine. 1980 Jan 1;9(1):135-43. [DOI:10.1016/0091-7435(80)90064-X]

30. Rasooli Ali Abadi B, Kalantari M. Based on acceptance and commitment therapy on depression, self-esteem and body image concerns, after the first birth, women in Kashan city. Avicenna J Nurs Midwifery care. 2018; $26 \quad$ (2) :103-112 [DOI:10.30699/s]hnmf.26.2.103]

31. Fallahchai R. Effectiveness of academic and life skills instruction on the freshmen academic achievement. Journal of Life science and biomedicine. 2012;2(4):137-41.

32. Shirkavand N, GHOLAMI HS, ARAB SZ, Ashoori J. The impact of life skills training on happiness and hopefulness among patients with type ii diabetes. 